\title{
Hypercalcemia in a Patient Diagnosed with a Vasoactive Intestinal Peptide Tumor
}

\author{
Basma Ataallah ${ }^{1,2}$, Barjinder S. Buttar ${ }^{3}$, Georgia Kulina ${ }^{4}$, Alan Kaell 5, 6, 3 \\ 1. Internal Medicine, Zucker School of Medicine at Mather, New York, USA 2. Internal Medicine, Northwell Health \\ Mather Hospital, New York, USA 3. Internal Medicine, Northwell Health Mather Hospital, Port Jefferson, USA 4. \\ Endocrinology, Northwell Health Mather Hospital, Port Jefferson, USA 5. Medicine, Renaissance School of Medicine, \\ Stony Brook University, Stony Brook, USA 6. Medicine, Zucker School of Medicine at Hofstra/Northwell, Hempstead, \\ USA
}

Corresponding author: Basma Ataallah, basma.b895@gmail.com

\begin{abstract}
Hypercalcemia is a clinical problem that is commonly seen in both the inpatient and outpatient settings. Overall, most common causes of hypercalcemia include hyperparathyroidism and malignancy. Our case report is the presentation of hypercalcemia in a patient eventually diagnosed with a vasoactive intestinal peptide tumor, a type of neuroendocrine tumor, without associated hyperparathyroidism.
\end{abstract}

Categories: Endocrinology/Diabetes/Metabolism, Internal Medicine, Oncology

Keywords: endocrinology, vasoactive intestinal peptide tumor, vipoma, hypercalcemia

\section{Introduction}

Neuroendocrine tumor (NET) is a rare and heterogeneous tumor type that makes up about $2 \%$ of all malignancies. The neuroendocrine system includes endocrine glands, such as the pituitary, parathyroid, and adrenals, as well as endocrine islet tissue embedded within the thyroid or pancreas [1]. Tumors can develop from any one of these sites.

Vasoactive intestinal peptide tumor (VIPoma) is a type of NET that continuously secretes VIP. They originate in cells of the gastroenteropancreatic endocrine system and in adrenal or extra-adrenal neurogenic sites. They are mainly found in the body and tail of the pancreas in $90 \%$ of the cases and the tumors tend to be greater than $3 \mathrm{~cm}$ in diameter [2]. About 60 to $80 \%$ of the VIPomas are malignant and have metastasized at the time of diagnosis. The main metastatic site is the liver, but the lymph nodes, lungs, and kidneys may be involved as well. The classic presentation is watery diarrhea, hypokalemia, and achlorhydria, also known as WDHA syndrome [3].

Received 01/02/2020 Review began 01/31/2020 Review ended 02/01/2020 Published 02/04/2020

\section{() Copyright 2020}

Ataallah et al. This is an open access article distributed under the terms of the Creative Commons Attribution License CC-BY 4.0., which permits unrestricted use, distribution, and reproduction in any medium, provided the original author and source are credited.
VIPoma are rare tumors with an overall incidence of $0.05 \%$ to $2.0 \%$. Only $5 \%$ of patients with VIPomas and hypercalcemia have a diagnosis of multiple endocrine neoplasia type 1 (MEN1) syndrome [4]. We present a young female who was admitted with hypercalcemia and found to have metastatic malignant VIPoma without MEN-1 hyperparathyroidism.

\section{Case Presentation}

A 22-year-old female with celiac disease, osteopenia, and depression presented with a two-month history of worsening diffuse abdominal pain, diarrhea, and arthralgia. The patient denied fever, chills, unintentional weight loss, or a history of recent travel. Outpatient labs were significant for a calcium of $15 \mathrm{mg} / \mathrm{dL}$ (8.5-10.2 $\mathrm{mg} / \mathrm{dL}$ ), a phosphate of $2.1 \mathrm{mg} / \mathrm{dL}(2.5-4.5 \mathrm{mg} / \mathrm{dL})$, a potassium of $3.2 \mathrm{meq} / \mathrm{L}$ (3.5-5 meq/L), a non-anion gap hyperchloremic metabolic acidosis with chloride of $116 \mathrm{meq} / \mathrm{L}$, a bicarbonate of $18 \mathrm{meq} / \mathrm{L}$, a normal anion gap of $8.5 \mathrm{meq} / \mathrm{L}$ corrected for a low albumin of $3 \mathrm{~g} / \mathrm{dL}$, and minimally elevated alanine aminotransferase of $61 \mathrm{U} / \mathrm{L}(7-56 \mathrm{U} / \mathrm{L})$ and aspartate aminotransferase of $55 \mathrm{U} / \mathrm{L}(10-40 \mathrm{U} / \mathrm{L})$ with normal alkaline phosphatase and bilirubin.

Upon presentation, she was afebrile, and her blood pressure, pulse rate, and respiratory rate were observed to be $120 / 70 \mathrm{mmHg}, 80$ beats/minute, and 17 breaths/minute, respectively. Physical examination was notable for mild diffuse abdominal tenderness without signs of rebound. The patient was admitted for evaluation and treatment of severe hypercalcemia. Throughout the hospital course, the calcium improved to $13.9 \mathrm{mg} / \mathrm{dL}$ with intravenous normal saline and correction of electrolytes. An abdominal ultrasound revealed two heterogeneous masses in the right hepatic lobe of the liver measuring 7.4 and $8.5 \mathrm{~cm}$. MRI of the abdomen without contrast, followed by MRI abdomen with contrast, confirmed a large, solid, pancreatic tail lesion with liver metastases as shown in Figure 1 [T2]. 


\section{Cureus}

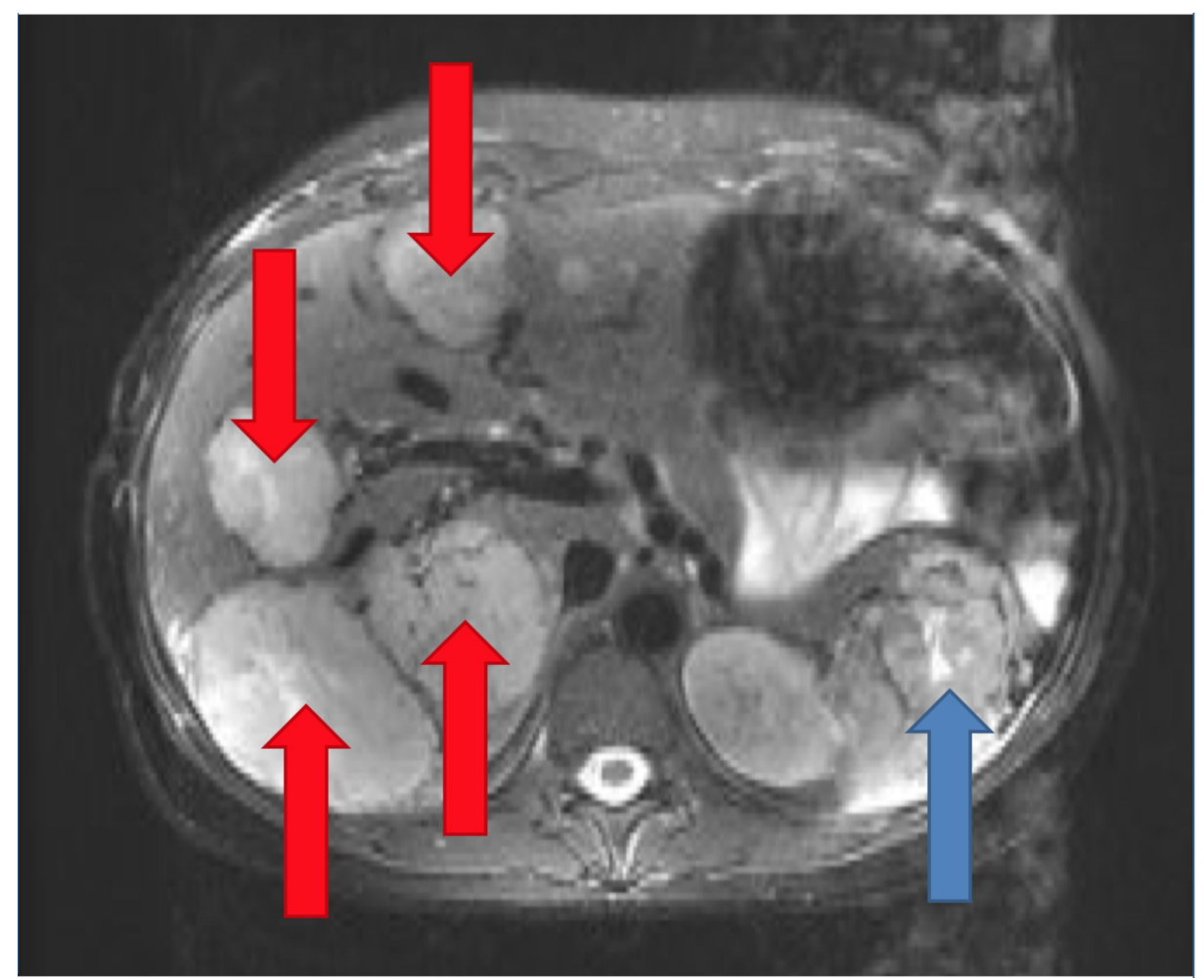

\section{FIGURE 1: Magnetic Resonance Imaging of the Abdomen}

Significant for a large, predominantly solid, pancreatic tail lesion with central necrosis (blue arrow). Large liver lesions are present in the majority of the segments of the liver suggesting neuroendocrine metastases (red arrows).

Additional labs included undetectably low iPTH (intact parathyroid hormone), low PTHrP (parathyroid hormone related peptide), normal renal function, mildly decreased vitamin D of $24 \mathrm{ng} / \mathrm{mL}$, and normal blood glucose level. She was found to have a markedly elevated VIP level of greater than $900 \mathrm{pg} / \mathrm{mL}(0-60 \mathrm{pg} / \mathrm{mL})$. The diagnosis of hypercalcemia attributed to malignant pancreatic VIPoma with liver metastasis was established. She was given a dose of $4 \mathrm{mg}$ zoledronic acid, which improved her hypercalcemia significantly. She was referred for surgical resection and medical management of her VIPoma with octreotide.

\section{Discussion}

Hypercalcemia can be associated with VIPomas. Of those VIPoma patients with hypercalcemia, up to $5 \%$ have treatable hyperparathyroidism associated with MEN-1. The calcium level seen with hyperparathyroidism is typically in the mild range of 10.5 to $11 \mathrm{mg} / \mathrm{dL}$ [5]. The majority of VIPomas with hypercalcemia are not attributed to MEN-1 associated hyperparathyroidism. Those cases, as in our patient, have higher calcium levels. Despite the presence of hypercalcemia, patients with VIPoma present with WDHA and not constipation as would be expected in all other cases of hypercalcemia.

Although the pathophysiology of hypercalcemia in VIPoma is unclear, lytic bone lesions do not appear to be a factor even with malignant metastatic VIPomas. The elevated calcium may be multifactorial: dehydration and electrolyte disturbances secondary to diarrhea, secretion by the tumor of a calcitrophic peptide, or bone resorption or PTH-like effects of high VIP levels. [6]

In the setting of VIPoma with hypercalcemia, treatment includes correcting volume and electrolyte abnormalities, calcitonin, and bisphosphonates.

\section{Conclusions}

Our case of a young female, diagnosed first with hypercalcemia, and presenting with the classic WDHA syndrome, was found to have a malignant metastatic VIPoma. Hyperparathyroidism as a part of MEN-1 syndrome was excluded and, therefore, parathyroidectomy not considered. Malignant VIPoma should be considered as a rare but possible underlying cause of patients presenting with similar symptoms. 


\section{Cureus}

\section{Additional Information}

\section{Disclosures}

Human subjects: Consent was obtained by all participants in this study. Conflicts of interest: In compliance with the ICMJE uniform disclosure form, all authors declare the following: Payment/services info: All authors have declared that no financial support was received from any organization for the submitted work. Financial relationships: All authors have declared that they have no financial relationships at present or within the previous three years with any organizations that might have an interest in the submitted work. Other relationships: All authors have declared that there are no other relationships or activities that could appear to have influenced the submitted work.

\section{References}

1. Oronsky B, Ma PC, Morgensztem D, Carter CA: Nothing but NET: a review of neuroendocrine tumors and carcinomas. Neoplasia. 2017, 19:991-1002. Accessed: Fenruary 19, 2020: https://doi.org/10.1016/j.neo.2017.09.002

2. VIPomas. (2017). Accessed: November 24, 2019: https://emedicine.medscape.com/article/125910-overview.

3. Fujiya A, Kato M, Shibata T, Sobajima H: VIPoma with multiple endocrine neoplasia type 1 identified as an atypical gene mutation. BMJ Case Rep. 2015, 2015:bcr2015213016. Accessed: November 24, 2019: http://dx.doi.org/10.1136/bcr-2015-213016

4. Sandhu S, Jialal I: VIPoma. StatPearls, Treasure Island, FL; 2019.

5. Vinik A: Vasoactive intestinal peptide tumor. Endotext, South Dartmouth, MA; 2017.

6. VIPoma: clinical manifestations, diagnosis, and management. (2019). Accessed: November 24, 2019: https://www.uptodate.com/contents/vipoma-clinical-manifestations-diagnosis-and-management. 